\title{
The Importance of Functional Magnetic Resonance Imaging in Neurosurgical Treatment of Tumors in the Central Region
}

\author{
Dirk Winkler', Gero Strauss², Dirk Lindner ${ }^{1}$, Andreas Richter $^{3}$, Margret Hund Georgiadis $^{4}$, \\ Yves von Cramon ${ }^{4}$, Jürgen Meixensberger ${ }^{1}$
}

\begin{abstract}
Background and Purpose: Localization of primary sensorimotor cortex is an important radiologic tool when approaching lesions involving eloquent regions. The clinical impact and efficacy of functional magnetic resonance imaging (fMRI) in image-guided surgery of tumors in the central region will be analyzed.

Patients and Methods: 104 patients were operated, 49 patients using fMRI and neuronavigation (group 1), and 55 patients using anatomic landmarks (group 2). In group 1 image fusion of functional and anatomic image data was performed automatically and manually by a special fusion software using anatomic landmarks and skin fiducials just before surgery (STP 4.0, Carl Zeiss, Oberkochen, Germany). In both groups tumor resection was done microsurgically and, as far as possible, completely. The comparison between both groups was based on their pre- and postoperative neurologic status as well as on the tumor entities: gliomas, meningeomas, and metastases.

Results: The group that benefited most clearly, but not significantly from the use of fMRI and neuronavigation was that of patients with gliomas $(p>0.05)$. Here, the percentage of postoperative deteriorations could be reduced from $40 \%$ to $23 \%$. The group of patients with metastases profited slightly from the use of fMRI and neuronavigation. The percentage of all patients with an identical and better surgery-associated neurology increased from $79 \%$ to $89 \%$. In the meningeoma group the number of patients with an identical and improved neurologic postoperative outcome was identical in both groups $(89 \%)$.

Conclusion: The greatest benefit of fMRI could be demonstrated in the treatment of gliomas. FMRI and neuronavigation can unreservedly be recommended for resection of centrally located gliomas. Otherwise, the use of fMRI and neuronavigation is a supplementary diagnostic and intraoperative measure to increase the patient's and surgeon's safety. Identification of functional eloquent regions is important in assessing the operative risk and in determining the optimal operative approach to the neurosurgically relevant lesion.
\end{abstract}

Key Words: fMRI $\cdot$ Neuronavigation $\cdot$ Glioma $\cdot$ Meningeoma $\cdot$ Metastases

Klin Neuroradiol 2005;15:182-9

DOI 10.1007/s00062-005-6415-5

\section{Die Bedeutung der funktionellen Magnetresonanztomographie bei der neurochirurgischen Therapie von Tumoren der Zentralregion}

\section{Zusammenfassung}

Die Lokalisation des primär sensormotorischen Kortex ist ein bedeutendes radiologisches Hilfsmittel bei Läsionen, die die Zentralregion erfassen. Die klinische Bedeutung und der Nutzen der funktionellen Magnetresonanztomographie (fMRT) im Rahmen der bildgestützten Chirurgie von Tumoren der Zentralregion soll analysiert werden. 104 Patienten wurden insgesamt operativ versorgt - davon 49 Patienten unter Zuhilfenahme des fMRT's und der Neuronavigation (Gruppe 1), 55

\footnotetext{
${ }^{1}$ Department of Neurosurgery, University of Leipzig, Germany,

2 Department of ENT, University of Leipzig, Germany,

${ }^{3}$ Department of Radiology, University of Leipzig, Germany,

${ }^{4}$ Max Planck Institute of Cognition and Neuroscience, Leipzig, Germany.
} 
Patienten anhand anatomischer Landmarken (Gruppe 2). In Gruppe 1 erfolgte die präoperative automatische und manuelle Fusion funktioneller und anatomischer Bilddaten mittels spezieller Fusionssoftware unter Verwendung von anatomischen Landmarken und Hautmarkern (STP 4.0, Carl Zeiss, Germany). In beiden Gruppen erfolgte soweit möglich eine komplette mikrochirurgische Tumorresektion. Der Vergleich beider Gruppen basiert auf dem prä- und postoperativen neurologischen Status der Patienten ebenso wie auf den einzelnen Tumorentitäten: Gliome, Meningeome und Metastasen. Die Gruppe, welche den größten, wenn auch nicht signifikanten Benefit von der Anwendung der fMRT und Neuronavigation hatte, war die der Gliompatienten $(p>0.05)$. In dieser Gruppe konnte der Prozentsatz der Patienten mit postoperativen Störungen von $40 \%$ auf $23 \%$ gesenkt werden. Die Gruppe der Metastasenpatienten profitierte leicht von der Anwendung der fMRT und Neuronavigation. Der Zahl der Patienten mit identischer und verbesserter OP-assoziierter Neurologie erhöhte sich von 79\% auf $89 \%$. In der Meningeomgruppe war mit $89 \%$ die Zahl der Patienten mit identischem und verbesserten postoperativen neurologischen Oucome identisch. Der größte Vorteil der Anwendung der fMRT konnte in der Gruppe der Gliome demonstriert werden. Die Kombination aus FMRT und Neuronavigation kann zur Resektion zentral lokalisierter Gliome empfohlen werden. Andernfalls stellt die Anwendung der FMRT und Neuronavigation eine ergänzende diagnostische und intraoperative Maßnahme dar, die Sicherheit für Patienten und Chirurgen zu erhöhen. Die Identifikation funktionell eloquenter Regionen ist wesentlich bei der Beurteilung des operativen Risikos und bei der Festlegung des optimalen operativen Zugangsweges zur neurochirurgisch relevanten Läsion.

Schlüsselwörter: fMRI · Neuronavigation · Gliom · Meningeom · Metastase

\section{Introduction}

With the computed tomography in the 70s, the digital processing of X-rays (digital subtraction angiography) and the development of magnetic resonance tomography the major prerequisites for subsequent computer assisted surgery were created. The basic idea behind the development was the attempt to attain more detailed resolution and more differentiated diagnostics to enable a later and safer intervention. The way to achieve an improvement of outcome is and continues to be an intervention based on multimodal imaging as well as use of robots in the future. The complex anatomy in the intracranial cavity and the requirement for exact and precise planning of operations and intraoperative orientation in the parenchymatous organ brain suggested that preoperatively acquired computer and magnetic resonance image data could be used in conjunction with suitable computer systems. In contrast to the conventional methods of surgery used up to now, the crucial advantage is that secondary image processing of preoperatively acquired image data allows exact detailed reproduction of structures of interest that need to be safeguarded and virtual definition of entry and target coordinates. This exact reproduction of the image data obtained enables definitive virtual planning of the access approach route. These systems added a new quality in that they allow anatomic and pathologic structures to be selectively marked, and selected contours, for instance functional eloquent regions, to be segmented. Besides direct cortical stimulation and phase rever- sal of somatosensory evoked potentials (SSEPs) [1, 5, 6, 14, 18-20], preoperative magnetoencephalography (MEG) $[2,10,11,16]$, positron emission tomography (PET), single-photon emission computed tomography (SPECT) $[4,9]$ and transcranial magnetic stimulation [3], the preoperative image fusion of functional magnetic resonance imaging (fMRI) as a noninvasive method to localize functional areas $[12,13,15]$ enables the possibility to transpose additional data to the surgical site. These contours can be reproduced in the eyepiece or on the display of the connected workstation. The use of multimodal image data like the fMRI increases the efficiency of navigational systems because of the fact, that the tumor and the functional area can better be delimited, thereby avoiding damage to the latter. However, the use of image data implementation is limited by the fact that the mass effect of the tumor entails a variation from the normal cortical structures, and an orientation solely on the basis of landmarks is not sufficient and leads to a sense of false security $[5,19]$. Notwithstanding the diversity of the preoperative diagnostic possibilities described and the euphoria with regard to the benefit aspired to, the question arises as to the justification for use of individual techniques. In particular, the integration of fMRI data in the navigationally supported surgery has to be discussed. The possible beneficial implications of functional image data for the neurologic outcome of the patient group with processes in or near the central region described in this study that received surgery contributes to a critical cost-benefit analysis. 


\section{Patients and Methods}

Between 1995 and 2002 data of neurosurgical patients were documented prospectively for group 1 and retrospectively for group 2 . In both groups we investigated the postoperative outcome of patients, who were operated on a cortical or subcortical tumor lesion lying $\leq 15 \mathrm{~mm}$ away from the central sulcus or directly in the central region. In group 1 tumor resection was performed with preoperative fusion of anatomic and functional image data and neuronavigation compared to group 2, which was operated conventionally. In both groups tumor resection was done microsurgically and, as far as possible, completely. The number of patients with a microsurgically subtotal tumor removal was comparable: three gliomas in group 1 and three gliomas and one meningeoma in group 2, respectively. In cases, where a navigationally supported surgery was planned (group 1), two image series were acquired: the anatomic and functional image dataset. MRI datasets of a whole-body superconduction imaging system Magnetom "Vision" (Siemens, Erlangen, Germany), $1.5 \mathrm{~T}$, were acquired preoperatively as an anatomic dataset for planning of neuronavigational procedure and for localization of intracranial lesion. MRI data of $1 \mathrm{~mm}$ thickness with no interval between were taken. The FOV (field of view) was $25 \mathrm{~cm}$ using a $200 \times 256$ matrix. The T1-weighted three-dimensional (T1w 3-D) images were obtained with a repetition time of $11.4 \mathrm{~ms}$. In cases of enhancing lesions known from former investigations, Gd-DTPA (Magnevist ${ }^{\circledR}$, Schering, Berlin, Germany) was administered $(0.1 \mathrm{mmol} / \mathrm{kg}$ body weight). A total of $250 \mathrm{~T} 1 \mathrm{w} 3-\mathrm{D}$ images per patient was used for data processing, which occurred by means of

Table 1. Neuropathologic findings of tumors resected in the conventionally operated group (group 2), compared to group 1 as a combination of neuronavigation and implementation of fMRI.

Tabelle 1. Neuropathologische Ergebnisse der Tumoren, die in beiden Gruppen, d.h. konventionell (Gruppe 2) und in Kombination von Neuronavigation und fMRT (Gruppe 1) operativ entfernt wurden.

\begin{tabular}{lccl}
\hline Tumor entity & $\begin{array}{l}\text { Total } \\
(\mathbf{n})\end{array}$ & $\begin{array}{l}\text { Group 1 } \\
(\mathbf{n})\end{array}$ & $\begin{array}{l}\text { Group 2 } \\
(\mathbf{n})\end{array}$ \\
\hline Meningeoma & 37 & 18 & 19 \\
Metastasis & 28 & 9 & 19 \\
Glioma & 39 & 22 & 17 \\
- Astrocytoma (WHO II) & 11 & 7 & 4 \\
- Astrocytoma (WHO III) & 9 & 5 & 4 \\
- Glioblastoma (WHO IV) & 19 & 10 & 9 \\
\hline Total & 104 & 49 & 55 \\
\hline
\end{tabular}

a specific software program of STP version 3.5 and 4.0 (Carl Zeiss, Oberkochen, Germany). Data were transferred from the MRI scanner via network connection or magnetic optical disk (MOD) to the neuronavigation workstation. Functional image datasets for identification of the motor cortex were acquired in a 3-T MRI (Bruker, Ettlingen, Germany) and a 1.5-T MRI (Siemens, Erlangen, Germany), respectively. For fMRI acquisition changes of cerebral blood oxygenation, a technique known as BOLD (blood oxygenation level-dependent) contrast was used. The image acquisition was based on utilizing deoxyhemoglobin as an endogenous contrast medium. The functional area of the motor cortex was identified by special exercise tasks consisting of cyclic voluntary movements of extremities [7,8]. It is well established that changes in regional brain perfusion associated with neuronal activity can be visualized by fMRI.

Contouring of interesting regions (tumor) and structures of risk (vessels, ventricles) as well as the image fusion of anatomic and functional image data (central sulcus, functional area) were realized manually and automatically using a special software program (STP version 3.5 and 4.0, Carl Zeiss) slice by slice. Postprocessing features of neuronavigation, including special visualization of tumor and functional region, 3-D reconstruction, section modes, and zoom functions, were permitted preoperatively for exact simulation of the planned surgical approach, exposure, and definition of the optimal site and extension of the craniotomy. Preoperative overlapping of anatomic and pathologic findings in relation to functional eloquent regions could help to give a more complete preoperative impression of the region of interest. Neurologic examination of all patients was performed preoperatively and up to 6 months postoperatively. Subdivision into the two groups and three tumor entities, gliomas, meningeomas, and metastases, was performed prospectively.

\section{Results}

A total of 104 patients with a tumor-suspected structure in or near the central region was included in a prospective study. Of these, 49 patients were operated navigationally with the help of preoperatively acquired fMRI (group 1). 55 patients underwent conventional surgery without navigational system and additional functional image data and thus belonged to the control group. Examining the two groups, the ratio of the individual tumor entities shown in Table 1 can be discerned. The sex and age distribution of both groups was comparable and 
Table 2. Characteristics (sex, age, mean age) of the two patient populations (group 1, group 2) in comparison.

Tabelle 2. Patientenangaben (Geschlecht, Alter, Durchschnittsalter) beider Populationen (Gruppe 1, Gruppe 2) im Vergleich.

\begin{tabular}{llll}
\hline Sex and age & Total & Group 1 & Group 2 \\
\hline Male $(n)$ & 51 & 23 & 28 \\
Female $(n)$ & 53 & 26 & 27 \\
Mean age (years) & 53.03 & 53.88 & 52.27 \\
Age range (years) & $14-78$ & $14-78$ & $21-76$
\end{tabular}

is shown in Table 2. The outcome category (i.e., "improved", "unchanged", or "deteriorated") determined for up to 6 months after the operation was the crucial criterion for the effectiveness of the method used in group 1 . The performance deficits as a characteristic for the sensorimotor cortex were evaluated. The extent of tumor resection depended on the entity and positional relationship to the sensorimotor cortex which were expected on the basis of the image morphology. The following result, which reflects the influence of neuronavigation and the use of fMRI, was shown in the in-

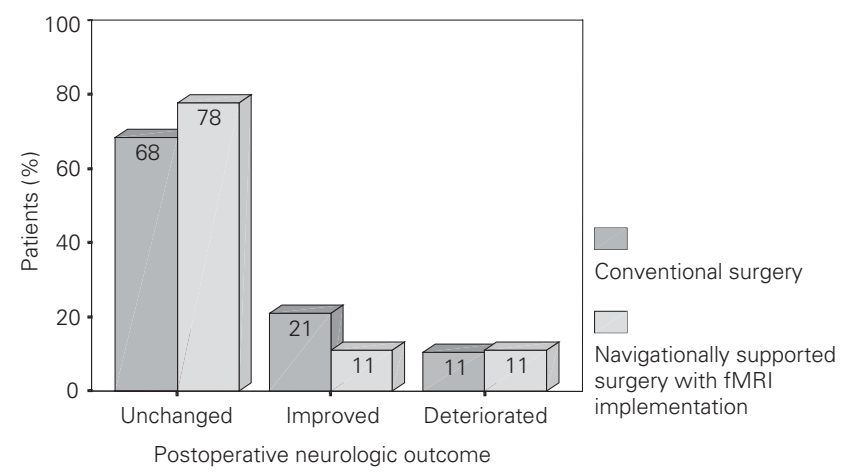

Figure 1a - Abbildung 1a

Figures 1a to 1c. Comparison of the two groups, operated navigationally supported (group 1) and conventionally (group 2), in all three tumor entities: meningeomas (a), metastases (b), and gliomas (c). Differences in the postoperative neurologic outcome ( 6 months postoperatively) in all tumor entities between both neurosurgical procedures were statistically not significant $\left(\chi^{2}\right.$ test) but showed, especially in the glioma group, a clear beneficial effect of neuronavigation, combined with implementation of $\mathrm{fMRI}$.

Abbildungen 1a bis 1c. Vergleich beider Gruppen, die sowohl navigationsgestützt (Gruppe 1) als auch konventionell (Gruppe 2) operiert wurden, hinsichtlich der Tumortentitäten: Meningeome (a), Metastasen (b) und Gliome (c). Die Unterschiede im postoperativen neurologischen Outcome (6 Monate postoperativ) waren in allen untersuchten Tumorentitäten zwischen beiden Gruppen nicht signifikant $\left(\chi^{2}\right.$-Test), zeigten aber speziell in der Gliomgruppe einen deutlich positiven Effekt der Neuronavigation in Verbindung mit der Implementation von fMRT-Datensätzen. vestigation: the navigationally supported treatment of meningeomas in or near the central region was associated with a deterioration in only $11 \%$ and was identical in the two groups (Figure 1). The number of patients with an identical neurologic outcome increased from $68 \%$ to $78 \%$ and decreased from $21 \%$ to $11 \%$ in cases of an improved neurologic status. The metastasis group profited slightly from the use of navigation and the implementation, i.e., the percentage of all patients with an identical and better neurologic outcome increased from $79 \%$ to $89 \%$ - in detail, there was a shift of the percentage of patients with an improvement from $16 \%$ to $22 \%$. Those with an identical finding increased from $63 \%$ to $67 \%$, corresponding to a reduction of patients with a neurologic deterioration from $21 \%$ to $11 \%$. The benefit of a navigation-assisted treatment with integration of functional image data was most convincing in surgical treatment of gliomas. The percentage of postoperative deteriorations fell from $40 \%$ to $23 \%$, which was not statistically significant $\left(\chi^{2}\right.$ test; $p>0.05$ ), but reflects a definite trend. The percentage with improved or identical state changed from $29 \%$ to $9 \%$ and from $29 \%$

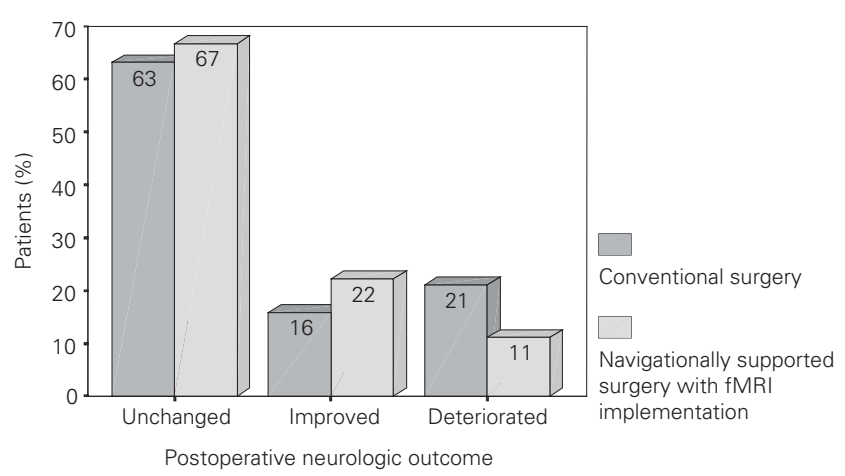

Figure $\mathbf{1 b}$ - Abbildung $\mathbf{a b}$

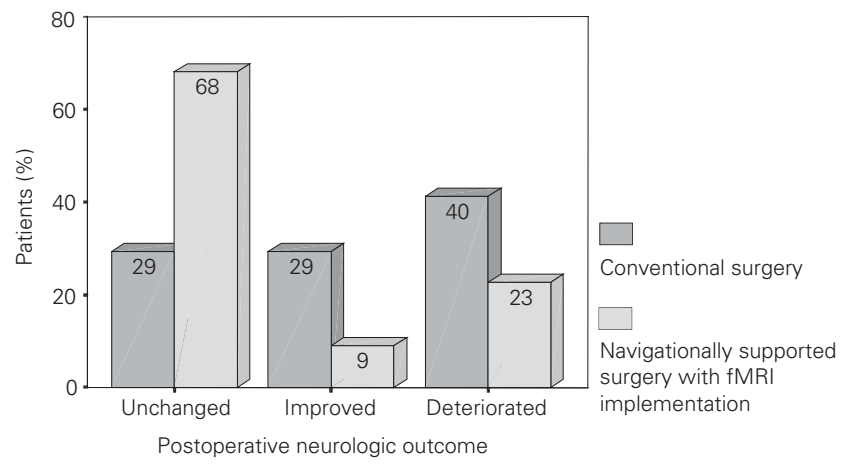

Figure 1c-Abbildung 1c 
to $68 \%$, respectively. Further details are available from Figures 1a to 1c.

\section{Discussion}

Neuronavigation is a variant of image-supported surgery. Current developments of navigation systems allow a wide variety of maneuvers of preoperative implementations of image data, intraoperative control as well as an adaptation of the planned procedure to the prevailing situation. Neuronavigational features, such as preoperative contouring, 3-D reconstruction, image fusion, virtual simulation, and the capacity to plan surgical procedures, as well as intraoperative multiplanar guidance, all have an influence on the surgical strategy, and can help to improve neurosurgical performance and clinical outcome. Additional postprocessing procedures, such as surface and volume-rendering techniques, coloring of 3-D objects, capacity for 3-D rotation and tumor volume measurement, all assist in the visualization of significant anatomic and complex structures; these techniques can be used for the delineation of structures of interest, and

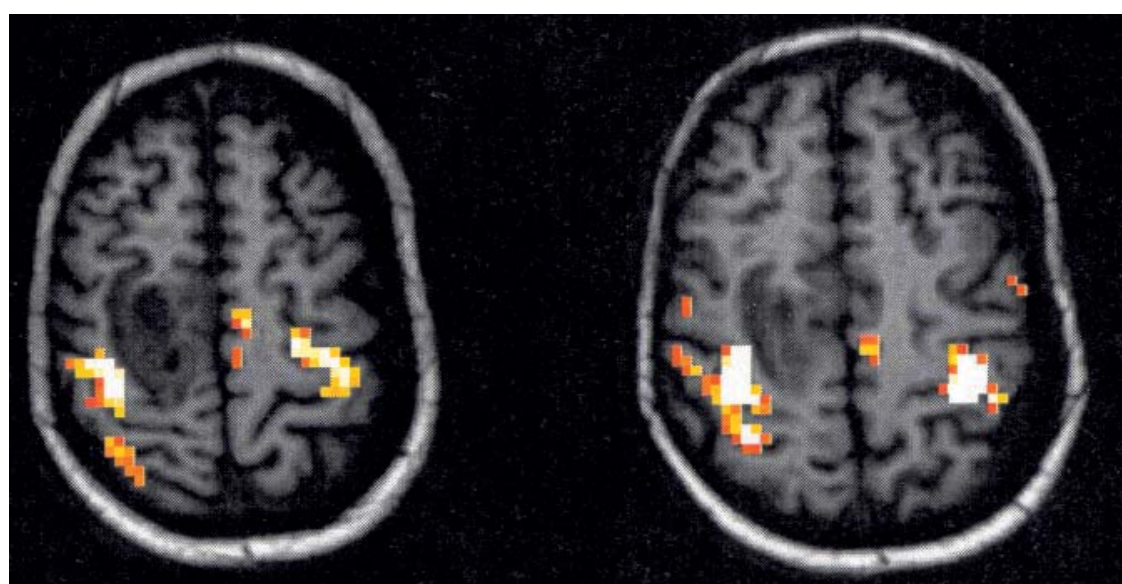

Figure 2. Clinical findings of this 48-year-old female patient with a right precentral tumor lesion (metastasis) at the time of admission were headache, vertigo and a latent hemiparesis of the left extremities. Before surgery and complete microsurgical resection, acquisition of $\mathrm{fMRI}$ data was done. Functional images were acquired on a 3-T Bruker MRI. Using fMRI, the motor cortex of the hand region was identified. The exercise task consisted of cyclic voluntary finger flexion performed with both hands. Location of exercise-correlated voxels during protocol, overlaid on selected slices of the patient. Color of correlated pixels is an index of relative signal intensity (red > orange $>$ yellow).

Abbildung 2. Die klinischen Beschwerden dieser 48 Jahre alten Patientin mit einer rechts präzentralen Tumorläsion (Metastase) zum Zeitpunkt der Aufnahme waren Kopfschmerzen, Schwindel und eine latente Hemiparese links. Vor der neurochirurgischen kompletten Entfernung des Tumors erfolgte die Akquisition von fMRT-Datensätzen in einem 3-T Bruker-MRT. Mittels fMRT erfolgte hierbei die Lokalisation des motorischen Handareals basierend auf zyklischen Fingerbewegungen beider Hände. „Übungskorrelierte“ Voxels wurden späterhin mit ausgesuchten MRT-Schnittebenen fusioniert, wobei die Farbe der so korrelierten Pixels der relativen Signalintensität (rot > orange > gelb) entspricht. for simulation of the surgical exposure using multiplanar postoperative sensorimotor deficits. In view of the neurosurgical risk as well as the time and costs associated with the use of neuronavigation, the following questions should be answered: (1) is the use of fMRI in connection logic deficits? and (2) in what group of patients does the

\section{Combination of $\mathrm{fMRI}$ and Neuronavigation}

The intraoperative visual identification of the pre- and postcentral gyri may be extremely difficult in cases in which the tumor manifestation is associated with a dislocation of sensorimotor cortex and anatomic landmarks are not usable. Variations in topography, obliteration of surface markings, by glial tumors in particular, and displacement by tumor mass contribute to this difficulty particularly with relatively small craniotomies. Image-guided navigation systems, based on preoperatively acquired anatomic and functional image datasets can help to visualize functional eloquent regions pre- and intraoperatively (Figures 2 and 3) $[17,19]$. In the following discussion, patients with an improved and identical neurologic status are grouped together and compared to those with deterioration: the neurologic outcome was identical in the neurosurgical treatment of meningeoma patients in both groups. It is primarily the excellent image of the tumor after craniotomy and the associated relatively reliable avoidance of damage to the adjacent sensorimotor cortex that may explain these favorable 


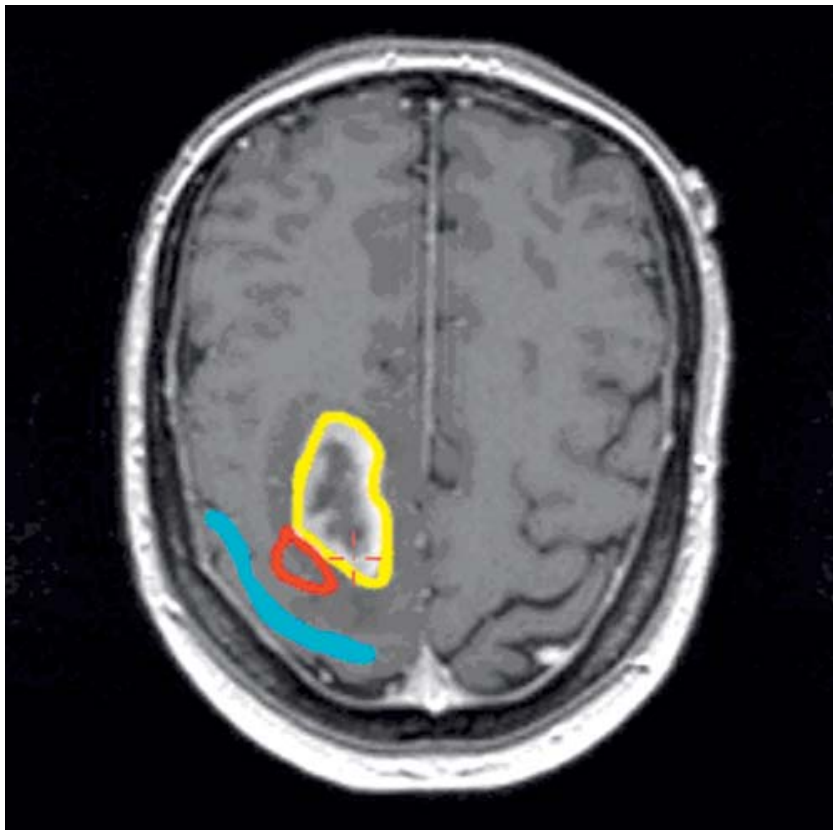

Figure $3 a$ - Abbildung $3 a$

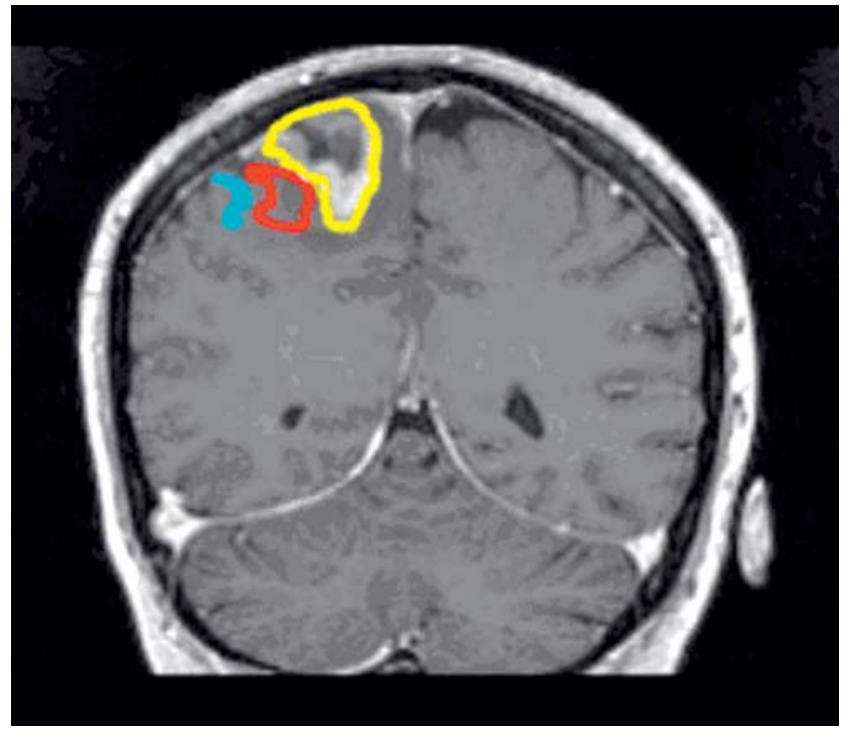

Figure $3 b-$ Abbildung $3 b$

Figures $3 \mathbf{a}$ and $\mathbf{3} \mathbf{b}$. T1w gadolinium-enhanced axial (a) and coronal (b) MRI scans of the same patient. An image fusion of preoperatively acquired anatomic MRI scans (Magnetom “Vision", 1.5 T, Siemens), which provides excellent spatial resolution of head and brain anatomy and functional image data, was realized using software program of STP version 4.0 (Carl Zeiss). The yellow line represents the tumor area, the blue line the central sulcus and the red line the functional motor cortex. All contours were implemented in the microscope's ocular during surgery. At the time of surgery, the central sulcus was clearly identified by phase reversal of the cortical recording of SSEPs. The cortical anatomy and the maximum SSEP location demonstrated a very good agreement with the preoperatively acquired fMRI. The intraoperative identification of the premotor cortex by direct cortical electrical stimulation supported our findings. Intraoperative monitoring completed identification of motor cortex and compensated intraoperative cortical shifting. Postoperatively, the patient recovered completely with full strength in all extremities and without additional neurologic deficits.

Abbildungen $3 \mathbf{a}$ und $\mathbf{3}$ b. T1w-Gadolinium-anreichernde axiale (a) und koronare (b) MRT-Scans ein und derselben Patientin. Die Bildfusion von funktionellen und präoperativ akquirierten anatomischen MRT-Bilddaten (Magnetom „Vision“, 1.5 T, Siemens, Erlangen, Germany), die eine exzellente Detailauflösung von Kopf- und Hirnanatomie lieferten, wurde mittels STP 4.0 (Carl Zeiss, Oberkochen, Germany) Fusionssoftware realisiert. Die gelbe Linie repräsentiert dabei das Tumorareal, die blaue Linie den Sulcus centralis und die rote Linie den funktionellen Motorkortex. Alle Konturen wurden während des operativen Eingriffs in das OP-Mikroskop eingespiegelt. Während des neurochirurgischen Eingriffs konnte der Sulcus centralis mittels SSEP-Phasenumkehr identifiziert werden. Die kortikale Anatomie wie das Maximum der SSEP-Antwort demonstrierten dabei eine gute Korrelation zu den präoperativ akquirierten fMRT-Daten. Die intraoperative Identifikation des Motorkortex durch direkte kortikale Stimulation bestätigte das Ergebnis. Im Ergebnis trug das intraoperative Monitoring sowohl zur Lokalisation des Motorkortex als auch zur Kompensation der Hirn-Shift bei. Postoperativ erholte sich die Patientin vollständig, einschließlich einer vollen Kraftentfaltung in allen Extremitäten bei gleichzeitig fehlenden zusätzlichen neurologischen Defiziten.

results. The factor brain shift was relatively unimportant in initial orientation concerning the local conditions in the further course of surgery owing to good identification of the tumor tissue. In contrast to meningeoma patients, metastatic lesions were also found subcortically, so that use of neuronavigation can help to limit the degree of tissue traumatization especially in metastases which have not reached the cortical surface and partially explains the better neurologic result in this group. Apart from this, surgery of metastases was facilitated, since they were usually well delimited. The best benefit in neurologic outcome could be demonstrated using navigation and fMRI in glioma surgery. In the controls, the extent of resection of tumors of only moderately good delimitability was determined by the local conditions, anatomic landmarks and the experience of the surgeon. Moreover, additional information (that from fMRI) could be taken into consideration using navigation, and this explains the marked reduction of deficits. The functional areas located preoperatively in fMRI and intraoperatively by means of SSEPs or by stimulation correlated well in principle. They could be confirmed intraoperatively, as reported also by other authors $[4,16]$. Despite the benefit of fMRI and navigationally supported surgery which can be observed especially in glioma surgery, the reliability of the fMRI acquisition has to be discussed: since 
the method of fMRI is standardized, the sources of error in this technique (if present) are identical and only differ to a limited extent between the individual test subjects. Reliability is restricted by the patient's cognitive abilities and the deficits that are demonstrable preoperatively.

Despite the high theoretical exactness of neuronavigation devices, these systems reflect, however, the static „real state“. One of the disadvantages of these systems is the missing presentation of dynamic changes being associated with the operation, including the brain shift, although at present there are several attempts to compensate just this deficit by an accompanying ultrasound and intraoperative CT or MRI, respectively. A change in the area of surgery, e.g., due to loss of cerebrospinal fluid during the operation, tumor resection, cyst emptying or entry of air into the subarachnoid space which afterwards leads to a gravity-related displacement of brain tissue (brain shift), results in a disparity between datasets acquired preoperatively and the surgical site in question. Finally, the STP 4.0 system introduces a series of error possibilities that influence the overall accuracy of the localization (technical accuracy). Position or number of fiducial marker as well as their registration and the image fusion procedure can affect the accuracy and loss of additional information $[4,10]$. The head affixed in the Mayfield clamp may still be moved during trephination, which adds another error in localization. The system-associated accuracy of the digitizer and camera array has to be taken into account [10].

For the appraisal of the risk, the identification of functional eloquent regions was crucial in deciding on the optimal surgical approach route, evaluation of the operative risk, and the scale of neurosurgery. Moreover, use of fMRI in conjunction with neuronavigation is justified in the treatment of lesions which do not reach the brain surface and in which the navigation-assisted planning and practical performance of surgery may be associated with a minimization of the tissue traumatization associated with the operation. As observed by other authors, methods such as intraoperative monitoring should be used to compensate for uncertainties of navigation in order to further diminish the unavoidable traumatization of the surrounding brain tissue [14]. With the integration of data into surgical treatment, further options are becoming apparent.

\section{Conclusion}

Identification of functional eloquent regions is important in assessing operative risk and determining the optimal operative approach to the neurosurgically relevant lesion. Postoperative good results, especially in glioma surgery, justify preoperative fMRI, fusion of anatomic and functional image data, neuronavigation as well as intraoperative electrophysiological localization of central sulcus and motor cortex despite of additional cost and prolonged operative time. A further possibility could be the tumor resection in the open configurated MRI and the "real-time" image fusion of fMRI data to compensate for the intraoperative brain shift and to increase the surgical exactness.

\section{References}

1. Behrens E, Zentner J, van Roost D, et al. Subdural and depth electrodes in the presurgical evaluation of epilepsy. Acta Neurochir (Wien) 1994; 128:84-7.

2. Beisteiner R, Erdler M, Teichtmeister C, et al. Magnetoencephalography may help to improve fMRI brain mapping. Eur J Neurosci 1997; 9:1072-7.

3. Boroojerdi B, Foltys $\mathrm{H}$, Krings $\mathrm{T}$, et al. Localization of the motor hand area using transcranial magnetic stimulation and functional magnetic resonance imaging. Clin Neurophysiol 1999;110:699-704.

4. Braun V, Dempf S, Tomczak R, et al. Multimodal cranial neuronavigation: direct integration of functional magnetic resonance imaging and positron emission tomography data: technical note. Neurosurgery 2001;48:1178-82.

5. Cedzich C, Taniguchi M, Schäfer S, et al. Somatosensory evoked potential phase reversal and direct motor cortex stimulation during surgery in and around the central region. Neurosurgery 1996;38: 962-70.

6. De Salles AA, Swartz BE, Lee TT, et al. Subdural recording and electrical stimulation for cortical mapping and induction of usual seizures. Stereotact Funct Neurosurg 1994;62:226-31.

7. Fox PT, Raichle ME. Focal physiological uncoupling of cerebral blood flow and oxidative metabolism during somatosensory stimulation in human subjects. Proc Natl Acad Sci USA 1986;83:1140-4.

8. Frahm J, Merboldt KD, Hanicke W, et al. Brain or vein - oxygenation or flow? On signal physiology in fMRI of human brain activation. NMR Biomed 1994;7:45-53.

9. Fried I, Nenov VI, Ojemann SG, et al. Functional MR and PET imaging of rolandic and visual cortices for neurosurgical planning. J Neurosurg 1995;83:854-61.

10. Ganslandt 0 , Steinmeier $\mathrm{R}$, Kober $\mathrm{H}$, et al. Magnetic source imaging combined with image-guided frameless stereotaxy: a new method in surgery around the motor strip. Neurosurgery 1997;41: 621-8.

11. Kamada K, Oshiro 0, Takeuchi $F$, et al. Identification of central sulcus by using somatosensory evoked magnetic fields and brain surface MR images: three-dimensional projection analysis. J Neurol Sci 1993; 116:29-33.

12. Kim SG, Ashe J, Georgopoulos AP, et al. Functional imaging of human motor cortex at high magnetic field. J Neurophysiol 1993;69: 297-302.

13. Kim SG, Ashe J, Hendrich K, Ellermann JM, et al. Functional magnetic resonance imaging of motor cortex: hemispheric asymmetry and handedness. Science 1993;261:615-7.

14. Krombach GA, Spetzger U, Rohde V, et al. Intraoperative localization of functional regions in the sensorimotor cortex by neuronavigation and cortical mapping. Comput Aided Surg 1998;3:64-73. 
15. Ludman CN, Cooper TG, Ploutz-Synder LL, et al. Force of voluntary exercise does not affect sensorimotor cortex activation as detected by fMRI at 1.5 T. NMR Biomed 1996;9:228-32.

16. Nimsky C, Ganslandt 0 , Kober $\mathrm{H}$, et al. Integration of functional magnetic resonance imaging supported by magnetoencephalography in functional neuronavigation. Neurosurgery 1999;44:1249-56.

17. Nitschke MF, Melchert UH, Hahn C, et al. Preoperative functional magnetic resonance imaging (fMRI) of the motor system in patients with tumours in the parietal lobe. Acta Neurochir (Wien) 1998;140: 1223-9.

18. Penfield W, Boldrey E. Somatic motor and sensory representation in the cerebral cortex of man studied by electrical stimulation. Brain 1937; 60:389-443.

19. Rowed DW, Houlden DA, Basavakumar DG. Somatosensory evoked potential identification of sensorimotor cortex in removal of intracranial neoplasms. Can J Neurol Sci 1997;24:116-20.
20. Wood CC, Spencer DD, Allison T, et al. Localization of human sensorimotor cortex during surgery by cortical surface recording of somatosensory evoked potentials. J Neurosurg 1988;68:99-111.

\author{
Address for Correspondence \\ Dr. Dirk Winkler \\ Klinik für Neurochirurgie \\ Universität Leipzig \\ Liebigstraße 20 \\ 04103 Leipzig \\ Germany \\ Phone (+49/341) 971-7500, Fax -7509 \\ e-mail:wind@medizin.uni-leipzig.de
}

